\title{
The Impact of Purchase Intent, Word of Mouth Advertising and Skill Domain of Seller on Quality of Customer Relationship to Sale Life and Savings Insurance Policies (Case Study: Dana Insurance Co., Bushehr Province)
}

\author{
Mohsen Rezaei ${ }^{1}$, Karim Nemati ${ }^{1 *}$ \\ ${ }^{1}$ Department of Management, Qeshm Branch, Islamic Azad University, Qeshm, IRAN
}

*Corresponding Author: ashena2030@yahoo.com

Citation: Rezaei, M. and Nemati, K. (2017). The Impact of Purchase Intent, Word of Mouth Advertising and Skill Domain of Seller on Quality of Customer Relationship to Sale Life and Savings Insurance Policies (Case Study: Dana Insurance Co., Bushehr Province). Dutch Journal of Finance and Management, 1(2), 43. https://doi.org/10.29333/djfm/5819

Published: May 21, 2017

\begin{abstract}
The aim of this study was to investigate the impact of purchase intent, word of mouth advertising and skill domain of seller on quality of customer relationship to sale life and savings insurance policies on Dana Insurance Co., Bushehr. The research method was descriptive, correlation type. Its population included all employees, branch managers, sales network and customers of Dana Insurance Co., Bushehr. According to Morgan Table, there were randomly participated 200 subjects in the study. A questionnaire was used to collect data. The data were analyzed using Pearson correlation and regression. Results showed a significant positive relationship between purchase intent, word of mouth advertising and skill domain of seller with quality of customer relationship in Dana Insurance Co.
\end{abstract}

Keywords: purchase intent, word of mouth advertising, skill domain of seller

\section{INTRODUCTION}

Today challenging and competitive world of business makes managers to assess factors affecting continuity and success of their organizations. Meanwhile, enterprise sales forces play a key role in advancing organization's goals and creating competitive advantages because of their direct relationship with customers. Always, organizations effort to educate and train their sales force using suitable approaches such as resource-based approach, in order to create competitive advantages for organizations (Esmailipoor et al., 2012). In this connection, in some organizations, using methods to develop skills of employees, which sell products and services is one of their main tasks, has become more important because using more effective methods in the sections can success organization to achieve its objectives. One of these organizations is insurance companies that skills in sales and customers' satisfaction play a very important role to purchase insurance policies (Javanmard et al., 2009). As an indicator of the development, insurance industry has been considered as one of major economic institutions and it supports activities of other institutions, the other hand. In other words, this industry plays an important role in economic development by receiving and investing the received premiums. It also facilitates progress process with security and reliability for service activities, manufacturing activities, etc. in community. On the other hand, during insurance experience in the country, yet the industry has not achieved the desired growth and culture of insurance has not been common in Iran as it should be. This matter is determined through premium on whole country income and its contribution on participation of global premium (Divandari et al., 2008). Therefore, it is obvious 
Table 1. The model summary

\begin{tabular}{cc}
\hline Values & Statistics \\
\hline Pearson correlation coefficient & 0.396 \\
\hline Significance level & 0.000 \\
\hline Coefficient of determination & 0.157 \\
\hline The adjusted coefficient of determination & 0.152 \\
\hline
\end{tabular}

Table 2. ANOVA

\begin{tabular}{cccccc}
\hline Model & SS & df & MS & F & Sig. \\
\hline Regression & 11.389 & 1 & 11.389 & & \multirow{2}{*}{0.000} \\
\hline Remain & 61.379 & 198 & 0.310 & 36.738 & \\
\hline Total & 72.768 & 199 & & & \\
\hline
\end{tabular}

Table 3. Regression coefficients

\begin{tabular}{cccc}
\hline Variable & Parameter estimation & $\mathbf{t}$ & Sig. \\
\hline Intercept $\beta 0$ & 2.708 & 10.004 & 0.000 \\
\hline Skill domain $\beta 1$ & 0.367 & 6.061 & 0.000 \\
\hline
\end{tabular}

that our country is one of the least developed countries of the world in terms of insurance. Given the importance of this issue, efforts to promote and develop insurance culture in the country are striking matters. So, aim of this study was to investigate the impact of purchase intent, word of mouth advertising and skill domain of seller on quality of customer relationship to sale life and savings insurance policies on Dana Insurance Co., Bushehr.

\section{METHODOLOGY}

The research method was descriptive, correlation type. Its population included all employees, branch managers, sales network and customers of Dana Insurance Co., Bushehr. According to Morgan Table, there were randomly participated 200 subjects in the study. In implementation phase of the research, after primary explanation about the purpose and measuring instrument of the test, there was described how to answer for the participants in detail. About ethical considerations, after obtaining letter of satisfaction and providing necessary information, they were ensured that the received information will be only used in this research and of will be kept from any misuse. The used questionnaire in this study was extracted according to studies of Rajolina and Brgron (2009). The questionnaire contains 16 questions on the relationships between elements of the model.

The questionnaire's questions have been set up based on ordinal scale Likert five-point range that include disagree completely, disagree, no difference, agree and agree completely. It has been designed as classified and based on the research hypotheses. The questionnaire can measure variables such as confidence, customer satisfaction, customer knowledge, skill domain, willingness to purchase and word of mouth advertising. Due to the research objectives, there were analyzed questions of skill domain, willingness to purchase, word of mouth advertising and relationship quality. Professors and experts confirmed validity of the questionnaire. Cronbach's alpha was used to determine its reliability. The obtained alpha value for entire of the questionnaire was 0.879 ; while its value for skill domain, willingness to purchase and word of mouth advertising were $0.716,0.727$ and 0.736 respectively that shows good reliability of measurement tools. Pearson correlation and regression were used to analyze data. In all analyzes, $\mathrm{p}<0.05$ was considered as the significance level.

\section{RESULTS}

Kolmogorov-Smirnov Test showed normal distribution of data $(p>0.05)$. There was investigated the relationship between skill domain with quality of relationship. Table 1 presents the results.

In Table 1, the Pearson correlation coefficient is 0.396 and significance level is 0.000 that is less than 0.05 . It indicates a direct and significance relationship between skill domains with quality of relationship. Coefficient of determination is 0.157 that shows skill domains justifies about $16 \%$ of total changes in quality of relationship. Table 2 shows regression significant.

In Table 2, since the significance level of the test is 0.00 and it is less than the accepted error rate $(0.05)$, so regression is significant statistically. As regression was significant statistically, in the next step, there should be estimated coefficients of regression equation and determined their significance. For this purpose, there was used Student t-test.

According to the presented results in Table 3, significant level of variable of intercept is 0.00 and it is less than 0.05. The significant level of skill domain variable is 0.00 and it is less than 0.05 . Due to the estimated coefficient 
Dutch Journal of Finance and Management, 1(2), 43

Table 4. The model summary

\begin{tabular}{cc}
\hline Values & Statistics \\
\hline Pearson correlation coefficient & 0.449 \\
\hline Significance level & 0.000 \\
\hline Coefficient of determination & 0.202 \\
\hline The adjusted coefficient of determination & 0.198 \\
\hline
\end{tabular}

Table 5. ANOVA

\begin{tabular}{|c|c|c|c|c|c|}
\hline Model & SS & df & MS & $\mathbf{F}$ & Sig. \\
\hline Regression & 16.959 & 1 & 16.959 & \multirow{3}{*}{50.015} & \multirow{3}{*}{0.000} \\
\hline Remain & 67.136 & 198 & 0.339 & & \\
\hline Total & 84.095 & 199 & & & \\
\hline
\end{tabular}

Table 6. Regression coefficients

\begin{tabular}{cccc}
\hline Variable & Parameter estimation & $\mathbf{t}$ & Sig. \\
\hline Intercept $\beta 0$ & 2.114 & 7.083 & 0.000 \\
\hline Skill domain $\beta 1$ & 0.483 & 7.072 & 0.000 \\
\hline
\end{tabular}

Table 7. The model summary

\begin{tabular}{cc}
\hline Values & Statistics \\
\hline Pearson correlation coefficient & 0.469 \\
\hline Significance level & 0.000 \\
\hline Coefficient of determination & 0.220 \\
\hline The adjusted coefficient of determination & 0.216 \\
\hline
\end{tabular}

Table 8. ANOVA

\begin{tabular}{cccccc}
\hline Model & SS & df & MS & F & Sig. \\
\hline Regression & 15.593 & 1 & 15.593 & \\
Remain & 55.406 & 198 & 0.280 & & 0.000 \\
\hline Total & 70.999 & 199 & & 55.722 & \\
\hline
\end{tabular}

(0.367), which it is positive, it can be said that skill domain has a direct and meaningful relationship with quality of relationship and the estimated regression equation is as follows:

Quality of relationship $=2.708+0.367$ skill domain

There was examined the relationship between intent to purchase with quality of relationship. Table 4 presents the results.

In Table 4, the Pearson correlation coefficient is 0.449 and significance level is 0.000 that is less than 0.05 . It indicates a direct and significance relationship between intent to purchase with quality of relationship. Coefficient of determination is 0.202 that shows quality of relationship justifies about $20 \%$ of intent to purchase.

In Table 5, since the significance level of the test is 0.00 and it is less than the accepted error rate (0.05), so regression is significant statistically.

As regression was significant statistically, in the next step, there should be estimated coefficients of regression equation and determined their significance. For this purpose, there was used Student t-test.

According to the presented results in Table 6, significant level of variable of intercept is 0.00 and it is less than 0.05. The significant level of skill domain variable is 0.00 and it is less than 0.05 . Due to the estimated coefficient (0.483), which it is positive, it can be said that quality of relationship has a direct and meaningful relationship with intent to purchase and the estimated regression equation is as follows:

Intent to purchase $=2.114+0.483$ quality of relationship

There was examined the relationship between word of mouth advertising with quality of relationship. Table 7 presents the results.

In Table 7, the Pearson correlation coefficient is 0.469 and significance level is 0.000 that is less than 0.05 . It indicates a direct and significance relationship between mouth advertising with quality of relationship. Coefficient of determination is 0.220 that shows quality of relationship justifies about $20 \%$ of mouth advertising. In Table 8 , since the significance level of the test is 0.00 and it is less than the accepted error rate $(0.05)$, so regression is significant statistically.

As regression was significant statistically, in the next step, there should be estimated coefficients of regression equation and determined their significance. For this purpose, there was used Student t-test.

According to the presented results in Table 9, significant level of variable of intercept is 0.00 and it is less than 0.05. The significant level of skill domain variable is 0.00 and it is less than 0.05 . Due to the estimated coefficient 
Rezaei \& Nemati / The Impact of Purchase Intent, Word of Mouth Advertising and Skill Domain of Seller ...

Table 9. Regression coefficients

\begin{tabular}{cccc}
\hline Variable & Parameter estimation & $\mathbf{t}$ & Sig. \\
\hline Intercept $\beta 0$ & 2.248 & 8.289 & 0.000 \\
\hline Skill domain $\beta 1$ & 0.463 & 7.465 & 0.000 \\
\hline
\end{tabular}

(0.463), which it is positive, it can be said that quality of relationship has a direct and meaningful relationship with word of mouth advertising and the estimated regression equation is as follows:

Word of mouth advertising $=2.248+0.463$ quality of relationship.

\section{DISCUSSION AND CONCLUSION}

The aim of this study was to investigate the impact of purchase intent, word of mouth advertising and skill domain of seller on quality of customer relationship to sale life and savings insurance policies on Dana Insurance Co., Bushehr. Results showed a significant positive relationship between purchase intent, word of mouth advertising and skill domain of seller with quality of customer relationship. The findings are consisted with the obtained results by Kazem and Abdolah (2010) and Rajaobelina and Bergeron (2009). Quality of relationship is known as a set of intangible values that leads to the expected long-term relationship between parties. HennigThurau and Klee describe quality of relationship between customers and companies as follows: proportion of relationship with the needs of customers involved in this relationship. The concept is often known as a high level component. In studies, trust is introduced as one of main factors that play an important role in influencing customers to develop and maintain their relationships with service suppliers. Generally, it is considered as an important determinant of quality of relationships between buyer and seller (Rajaobelina and Bergeron, 2009). The relationship between service provider and customers depends on quality of interactions between them (Shaikh Ali and Ndubisi, 2010). Quality of the received service by customers as well as quality of their relationship with service provider or company provides positive outcomes for customers. On the other hand, quality of relationship is considered as customers' positive emotions to provider, their relationships with him with regard their trust and overall satisfaction from supplier ( $\mathrm{Ng}$ et al., 2011). According to the research results, it is suggested that insurance managers empower sales staff by holding training courses to provide grounds for more sales by maintaining framework of customer-oriented principles. To design an education course, the first step is to assess education to determine that a sale expert or representative needs which educations for success in insurance sale and marketing. After determining education needs, the next step is performance phase. In the step, education officer should analyze them by considering the provide information by experts. Education analysis means analyzing education issues. Then staff can market by considering the provided educations. Managers can provide the required information on insurance services, new sales strategies and so forth for staff by holding continuous training sessions for staff, in order to provide them with the skills, and encourage customers in a way that they satisfy from their repurchase and loyal them for repurchase. It is also recommended that they take necessary actions to improve and provide better services for customers using set up information systems for obtaining feedback from customers and their opinions on the current service. It leads that customer feel that his comments are important for insurance company and creates a sense of mutual understanding. The appropriate response to object of customers on delivery of services, quality of service and staff cooperation can provide fields for customer satisfaction. Proportion of insurance services with needs and expectations of customers cause that they believe that their comments are important for the company and its services has been formed based on their opinions. It makes customer feel that in case of any damage, company can compensate his damage in the best possible way that it leads to reduce his concerns and risks on possible damages and a good sense to use the provided services by the company.

\section{REFERENCES}

Divandari, A., Nikookar, Gh., Nahavandian, M. and Aghazadeh, H. (2008). Market-orientation and business performance in Iran. Journal of Business Management, 1(1).

Esmailpoor, H., Javanmard, H. and Bajelan, A. (2012). Examining the effect of respect and agreement on quality of the perceived relationship from clients of small health services' institutions (Case study: Arak dentistry). Journal of Marketing Management, 15(Summer), 131-147.

Javanmard, H. and Soltanzadeh, A. (2009). Investigating features of Internet and website brands and their impact on trust and loyalty of customers (Case study: purchasing cultural products through the Internet). Journal of Business Research Letter, 53, 225-256.

Ng, S., David, M. E. and Dagger, T. S. (2011). Generating positive word-of-mouth in the service experience. Managing Service Quality, 21(2), 133-151. https://doi.org/10.1108/09604521111113438 
Norizan, K. and Norasiah, A. (2010). The effect of perceived service quality dimensions on customer satisfaction, trust, and loyalty in e-commerce settings: A cross cultural analysis. Asia Pacific Journal of Marketing and Logistics, 22(3), 351-371. https://doi.org/10.1108/13555851011062269

Rajaobelina, L. and Bergeron, J. (2009). Antecedents and consequences of buyer-seller relationship quality in the financial services industry. International Journal of Bank Marketing, 27(5), 359-380. https:// doi.org/10.1108/02652320910979889

Shaikh Ali, S. H. and Ndubisi, N. O. (2010). The effects of respect and rapport on relationship quality perception of customers of small healthcare firms. Asia Pacific Journal of Marketing and Logistics, 23(2), 135-151. https://doi.org/10.1108/13555851111120452 